\title{
Is technical demography becoming less relevant? Two decade review of published articles in selected demography journals

\author{
Joshua O. Akinyemi ${ }^{1,2}$ \& Sunday A. Adedini ${ }^{1,3}$
}

\author{
${ }^{1}$ Demography and Population Studies Programme, Schools of Public Health and Social Sciences, \\ University of the Witwatersrand, Johannesburg, South Africa \\ ${ }^{2}$ Department of Epidemiology and Medical Statistics, College of Medicine, \\ University of Ibadan, Ibadan, Nigeria \\ ${ }^{3}$ Department of Demography and Social Statistics, Obafemi Awolowo University, \\ lle Ife, Nigeria \\ Email: odunjoshua@gmail.com
}

\begin{abstract}
Background: In this paper, we reviewed development in the field of technical demography and empirically demonstrate that there has been a decline in the proportion of technical demographic studies published in the last two decades.

Methods: All original articles published in nine demographic journals from Africa, Europe, Australia, Canada and United States were reviewed. We derived yearly aggregate for total number of articles and number of technical demographic papers from 1994 to 2015. We illustrated the trends in the proportion of technical demographic studies in a graph and also estimated the annual rate of decline using least square regression techniques.

Results: A total of 409I studies were published in 465 issues of the selected journals between 1994 and 2015 of which $37 \mathrm{I}(9.0 \%)$ were related to technical demography. The proportion of technical demographic papers declined gradually at an annual rate of $0.42 \%(\mathrm{Cl}=0.29-0.62)$ between 1994 (I2.0\%) and 2015 (I0.0\%).

Conclusion: Technical demography need to be strengthened in order to provide the critical data and evidence required to objectively monitor the post-2015 development goals.
\end{abstract}

Keywords: Technical demography, demographic estimation; demographic techniques; mortality; fertility.

\section{Introduction}

Hauser and Duncan (1959) defined demography as "study of the size, territorial distribution, composition of population, changes therein, and the components of such changes". This definition clearly portrays the interdisciplinary nature of demography. For instance, population change could be economical, sociological, biological, etc- all of which rests in another discipline (Xie, 2000). It is unequivocal that measurement, estimation and analysis are the bedrock of demography. This aspect of the field is also known as technical demography - the branch of the discipline that deals with the methods, techniques and measures used in demographic estimation and analysis (Ramakumar and Gopal, 1986). It constitutes the core of demography as a discipline. This is underscored by historical developments in the field. From John Graunt - life tables to Alfred J. Lotka (who first proved the stable population theory) and several others, the discipline has thrived on the innovations, theories and models developed in technical demography.

http://aps.journals.ac.za
The conventional sources of data for demographic estimation are vital registration systems (for continuous registration of births, deaths and marriages/divorce) and population censuses. Over the years, these data sources have been at different levels of advancement and completeness in different regions of the world. In the western countries, vital registration systems (VRS) and censuses have existed for long and sophisticated enough to provide reliable data for direct estimation of demographic parameters but the situation in developing countries especially sub-Saharan Africa is different. In the latter settings, though censuses were sometimes conducted, however, VRS were rare especially during the colonial and early independence era. To overcome this challenge, demographers led by William Brass and others pioneered the development of techniques for "indirect estimation" of demographic parameters. Indirect demographic estimation involves the use of methods and procedures to estimate demographic parameters from data that is defective, indirect or 
both (Brass and Coale, 1968, United Nations, 1983). Vital registration data could be defective as a result of low level of completeness in recording of births and deaths. Coverage and content errors such as age misstatement are common sources of defect in census data. Development of indirect techniques followed two pathways - search for methods to analyse data from defective traditional sources (surveys, census and VRS) and the use of indirect evidence on births and deaths. From the second path, a wide array of indirect techniques emerged from three ideas: (i) estimation of fertility from data on births in previous year and children ever born to women of childbearing age; (ii) estimation of infant and childhood mortality from data on children ever born and surviving; and (iii) the use of model life tables and stable populations to estimate fertility, mortality and adjusted age distributions (Brass and Coale, 1968). These three innovations have undergone refinements, extensions and different forms of adaptation and applications before it culminated in the publication of the popular Manual $X$ by the United Nations in 1983 (United Nations, 1983). Many of the techniques developed have also been applied in developed countries for assessment of the quality of census data, historical estimation of fertility and mortality rates. These efforts have enriched the subject of technical demography and the broader discipline as a whole.

In a commentary on the dying art of technical demography, Saxena (20II) alluded to the roles of the International Conference on Population and Development (ICPD) and further blamed the dwindling fortune on the replacement of technical demography courses by other topics on population and development. As a result, most demography and population studies graduates lack indepth knowledge of technical demography and therefore not adequately equipped to drive further development in the subject area. A paper presented at the Population Association of America annual meeting also decried the weak status of demographic training in South Africa amidst the hope of improved data quality in censuses and VRS in Africa as a whole (Pali, 2015). The situation is not much different in other African countries.

Though these problems are real, there has not been empirical evidence on the dearth of technical demographic research outputs in peer-reviewed publications. Meanwhile, it is opined that journal publication is not just a means of communication among researchers, it also reflects developments in a discipline (Keyfitz, 1993). This implies that one way to assess how the field of technical demography is faring is by checking articles published in relevant journals and quantifying the proportion of technical demographic studies therein. Therefore, in this review, we investigate the hypothesis that the proportion of technical demographic studies published in demographic journals has declined in the past two decades.

\section{Methods}

\section{Selection of journals}

In order to ascertain the percentage of technical demographic studies published between 1994 and 2015, we reviewed all publications in nine leading demographic journals: African Population Studies, Canadian Studies in Population, Demography, Demographic Research, GENUS, Journal of Population Research, Mathematical Population Studies, Population, and Population Studies. African Population Studies was launched in 1984 by the Union for African Population Studies while Canadian Studies in Population is published by the Canadian Population Society since 1974. Demography is published bi-monthly by the Population Association of America since 1964 while the Journal of Demographic Research was launched in 1999 by the Max Planck Institute for Demographic Research, Germany. GENUS is published by the University of Rome in Italy and was founded in 1934. Journal of Population Research formerly known as the Journal of the Australian Population Association till 1999, was first published in 1984. Mathematical Population Studies was founded by a group of mathematical demographers in 1988. Population Journal is published by Institut National D'etudes De'mographiques (INED) since 1946 while Population Studies is published at the London School of Economics since 1947. These journals were selected to reflect the various regions. Thus African Population Studies for Africa region; Demography, Mathematical Population Studies and Canadian Studies in Population for North and South America; Demographic Research, GENUS, Population and Population Studies for Europe; Journal of Population Research for Australia and Asia. These journals have international focus and do not restrict publication to papers from any region of the world.

For Population Journal, only issues published in 2002 onward were available and reviewed. Those for 1994-200 I were not available in the online archive of the journal. In addition, a few prominent Journals of Statistics (such as Journal of the American Statistical Association, Biometrics and Indian Statistical Journal) occasionally publish articles on technical demography. Further review of a few issues of these journals revealed that they published predominantly statistics related topics. If they were to be included, the proportion of technical demographic studies would be very small as a result of which the overall 
percentage of technical demography papers would be drastically reduced. To avoid the effect of this potential selection bias, these statistical journals were not included in the review.

\section{Sources and assessment of articles}

Articles published in Canadian Studies in Population, Demography, Journal of Population Research, Demographic Research, Mathematical Population Studies, Population, and Population Studies were obtained from the online archives of each journal. Articles published in GENUS were retrieved via JSTOR while those of African Population Studies were sourced from Bioline International- a free open access database.

All articles in every issue of the selected journals were screened to determine whether they could be classified as a technical demographic study. The screening process involve reviewing the abstract and method section of each article to ascertain whether it could be classified as technical study or not. For this review, an article was deemed to be technical if it involves the use of any concept in technical demography (methods, measures, and techniques of demographic analysis). As such, we included articles that involved demographic estimation (direct and indirect), life table techniques, population projections, and assesment of quality of census or survey data. Articles on family demography, historical demography and those that merely used advanced statistical models were not classified as technical demographic studies.
For each issue of the journal, we recorded information on the year of publication, volume, issue, total number of articles and number of technical demographic studies. The technical demographic studies were further sub-classified under mortality, fertility, nuptiality, migration, data quality assessment, projection and others (e.g. stable population theory, decomposition of changes in life expectancies, etc). We derived yearly aggregate for total number of articles and number of technical demographic studies for 1994 to 2015 and subsequently computed the proportion of technical studies for each year. We illustrated the trends in the proportion of technical demographic studies in a graph and also estimated the annual rate of decline using least square regression techniques.

\section{Results}

A total of 409I original studies were published in 465 issues of the selected journals between 1994 and 2015. The number of original articles in these journals grew at an exponential rate of $5.66 \%$ over the review period (Figure I). Table I shows that 93 (20.0\%) of the 465 issues were contributed by Demography Journal while Demographic Research had 33 (7.1\%). Overall, 37I (7.0\%) of the 4067 articles were based on technical demography. The proportion of technical demographic studies ranged from $12.0 \%$ in 1994 to $10.0 \%$ in 2015 (Table 2). Figure 2 shows that the proportion declined gradually at an annual rate of $0.42 \%(\mathrm{Cl}=0.29-0.62)$ between 1994 and 2015.

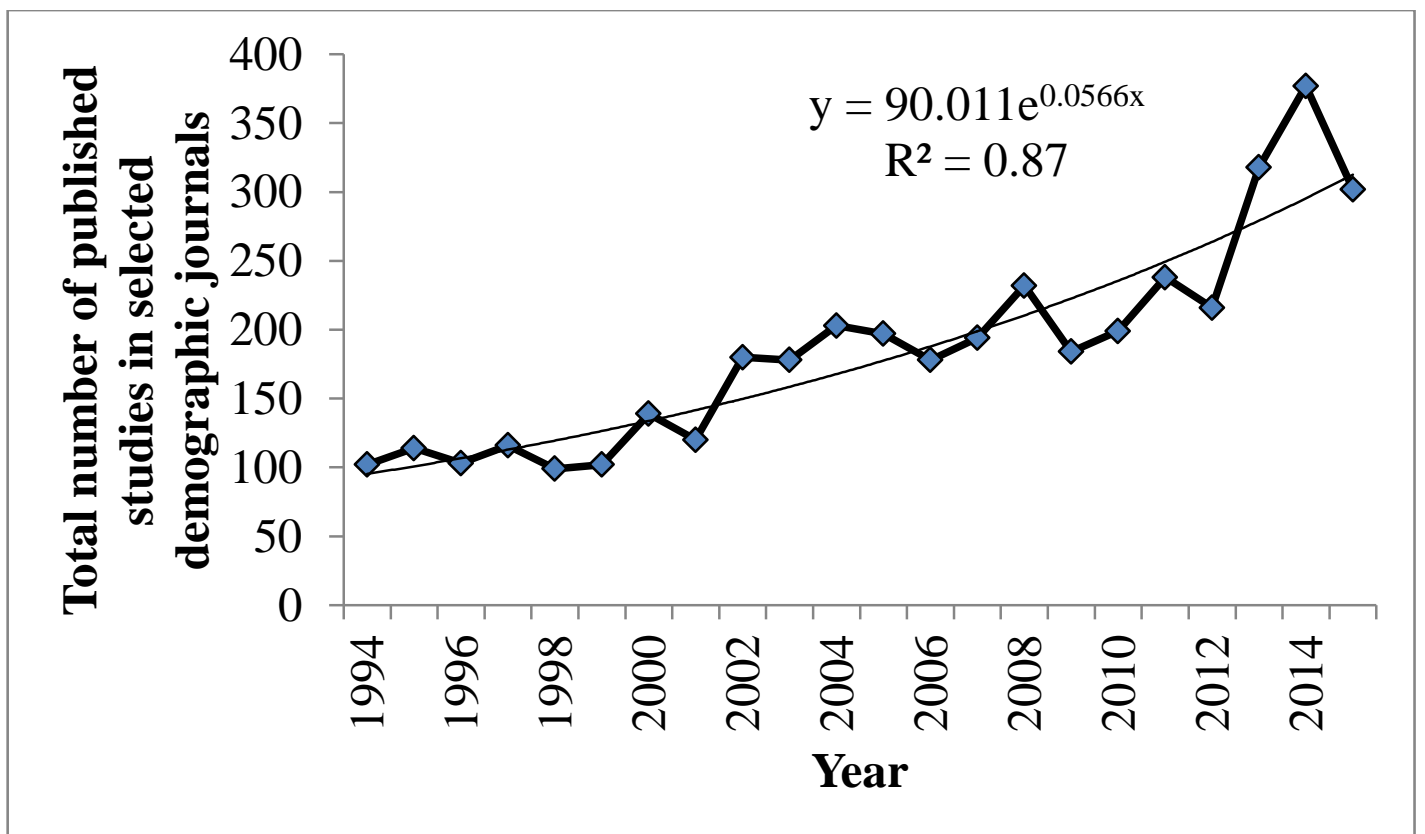

Fig I: Total number of original articles published in selected demographic journals, $1994-2015$ 
Table I: Table I: Number of issues published by major demographic journals, 1994-20I5

\begin{tabular}{lll}
\hline Journal & No of issues & Percentage \\
\hline African Population Studies & 36 & 7.7 \\
Canadian Studies in Population & 38 & 8.2 \\
Demographic Research & 33 & 7.1 \\
Demography & 93 & 20.0 \\
Genus & 50 & 10.8 \\
Journal of Population Research & 51 & 11.0 \\
Mathematical Population Studies & 43 & 9.2 \\
Population & 56 & 12.0 \\
Population Studies & 65 & 14.0 \\
\hline
\end{tabular}

\section{Source: Authors' review of selected journals}

The results further show that the technical demographic studies were devoted to mortality (44.2\%), fertility (23.9\%), data quality assessment and population projections ( $10.8 \%)$, migration
(8.0\%) and nuptiality (2.1\%). Other wide range of topics such as population momentum, stable population theory, relational life tables, etc constitute II.0\%.

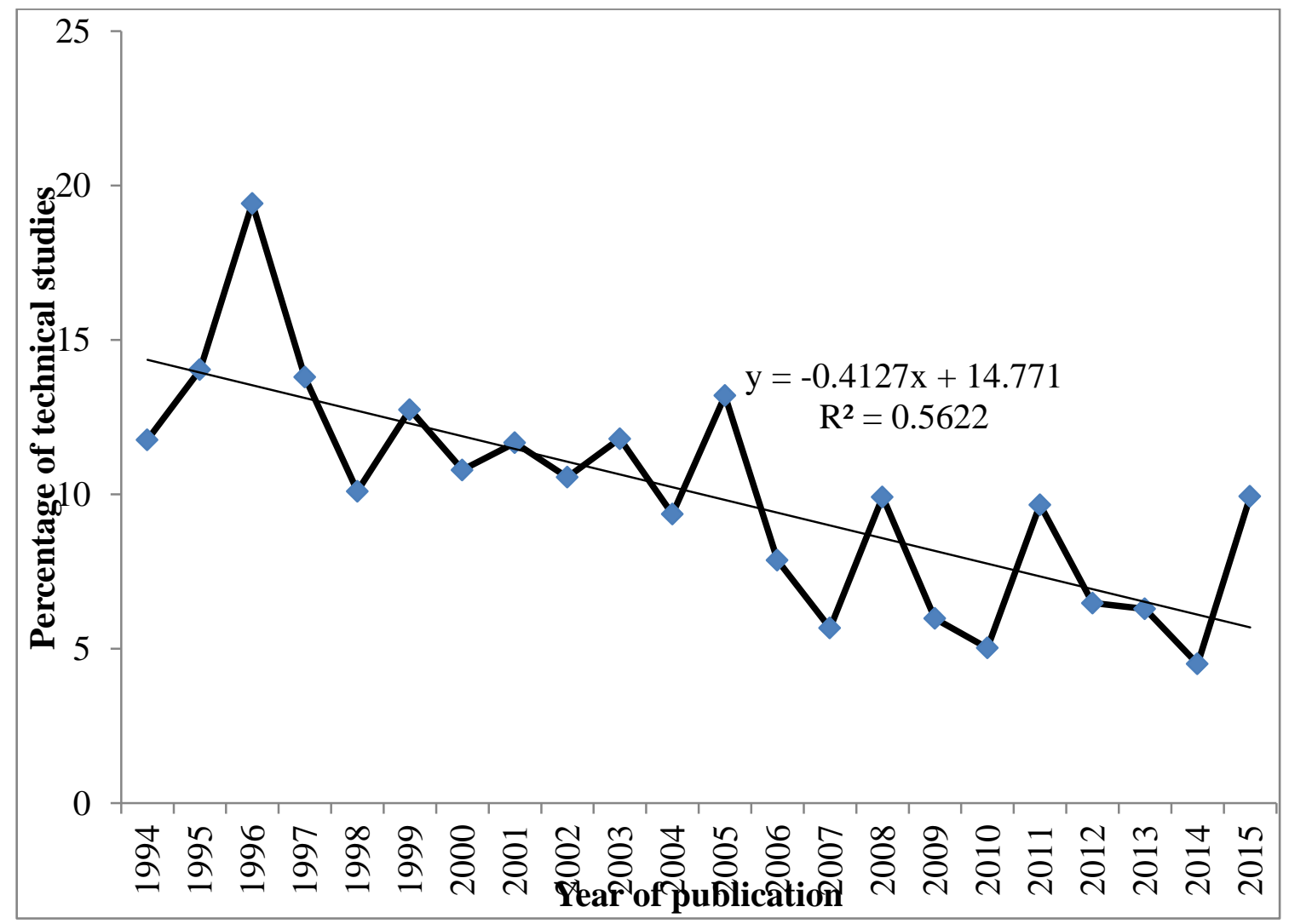

Fig 2: Trends in percentage of technical studies published in selected demographic journals, 19942015

Table 2: Summary of technical demographic studies published in major demography journals, 1994-20I5

\begin{tabular}{|l|l|l|l|}
\hline Year & Total no of studies & Technical studies & \% Technical \\
\hline 1994 & 102 & 12 & 12 \\
\hline 1995 & 114 & 16 & 14 \\
\hline 1996 & 103 & 20 & 19 \\
\hline 1997 & 116 & 16 & 14 \\
\hline 1998 & 99 & 10 & 10 \\
\hline
\end{tabular}




\begin{tabular}{|l|l|l|l|}
\hline 1999 & 102 & 13 & 13 \\
\hline 2000 & 139 & 15 & 11 \\
\hline 2001 & 120 & 14 & 12 \\
\hline 2002 & 180 & 19 & 11 \\
\hline 2003 & 178 & 21 & 12 \\
\hline 2004 & 203 & 19 & 9 \\
\hline 2005 & 197 & 26 & 13 \\
\hline 2006 & 178 & 14 & 8 \\
\hline 2007 & 194 & 11 & 6 \\
\hline 2008 & 232 & 23 & 10 \\
\hline 2009 & 184 & 11 & 6 \\
\hline 2010 & 199 & 10 & 5 \\
\hline 2011 & 238 & 23 & 10 \\
\hline 2012 & 216 & 14 & 6 \\
\hline 2013 & 318 & 20 & 6 \\
\hline 2014 & 377 & 17 & 5 \\
\hline 2015 & 302 & 30 & 10 \\
\hline Total & 4091 & 374 & 9 \\
\hline
\end{tabular}

Source: Authors' review of selected journals

The mortality studies covered infancy and childhood, adulthood and older ages. Many of the childhood mortality studies utilized techniques such as children ever born/child surviving method (Adetunji, 1996, Blacker et al., 2007), preceding birth technique (Aguirre, 1994, Bairagi et al., 1997), and hazard and frailty models(Bocquier et al., 20II, Sastry, 1997). For adult mortality, widowhood (Ahmed, 1995), sibling suvivorship (Gakidou and King, 2005, Masquelier, 2013), orphanhood methods (Grassly et al., 2004, Udjo, 20I4), Lee-carter model (Booth et al., 2006, Booth et al., 2002, Miller and Lee, 200I), method of extinct generation (Bourbeau, 2000, Elo, 200I, Guillot, 2003, Hill et al., 2005, Preston et al., 1999), survival ratio (Spoorenberg, 2008) and life tables (Kannisto et al., 1999, Kostaki and Panousis, 200I, Nath and Choudhury, 1995, Rowland, 1996, Zaba and Paes, 1995) were quite common. A few studies also explored new developments such as Bayesian extension to Lee-Carter model (Booth et al., 2006, Wisniowski et al., 20I5, Zhao, 20I2) and multi-dimensional life table method (Eini-Zinab, 2013). However, most of the latest developments have only been used in developed countries and applied to census and VRS data.

Fertility studies cut across different regions of the word and were based on censuses, surveys and VRS data. Analytical approaches included use of parity progression ratio (Kohler and Ortega, 2002, Moultrie et al., 2012, Sibanda, 1999), relational Gompertz model (Paget and Timaeus, 1994, Udjo, 1998, Udjo, 20I4), own-children method (Abbas-Shavazi, 1997, Avery et al., 2013, Dubuc, 2009), P/F ratio (Hinde and Mturi, 2000, Moultrie and Dorrinton, 2008, Moultrie and Timaeus, 2003, Udjo, 1998), variable-r method (Alkema et al., 20II, Cai, 2008), and Bongaarts model (Bongaarts, 1999, Kohler and Ortega, 2002, Odimegwu and Zerai, 1996). Lately, methods such as truncated cohort parity progression ratio and the own-children method were being applied in developed countries contrary to the belief that these techniques are for developing countries where reliable VRS are lacking (Avery et al., 2013, Dubuc, 2009).

Studies on population projections were also fairly common based on methods such as cohortcomponent projection and Bayesian approaches (Alkema et al., 20I I, Bocquier, 2005, Keilman et al., 2002, Thomas and Clark, 20II, Wisniowski et al., 2015). With the exception of South Africa (Udjo, 20I3, Udjo, 20I4, Udjo, 20I5), population projections were scarce for Sub-Saharan countries. A few migration studies were found but predominantly conducted in USA and Australia using an array of direct, indirect and open-stable population models applied to census data (Bell and Stratton, 1998, Wilson, 2010). The generalised growth balance method has also been applied in census data quality assessment (Bhat, 2002a, Bhat, 2002b, Williams, 2014).

\section{Discussion}

This review shows that whereas the number of original articles in the selected journals has increased exponentially, there has been a significant decline in the percentage of technical demographic studies since 1994. We also observed that some 
demographic topics such as population projection, census data quality assessment were rarely published for developing countries especially in sub-Saharan Africa. Censuses and vital registration systems were supposed to be the prime sources of demographic data for population projection, estimation of demographic parameters, monitoring of population policies. Unfortunately, these traditional sources of demographic data are very poor and unreliable in many developing countries (Mathers et al., 2005). VRS in most places are passive and level of completeness is low. Consequently, surveys have become popular alternatives though with their own inherent data quality challenges. These are strong reasons for indirect estimation techniques.

The exponential growth in the number of articles in demographic journals is not surprising given the different evolution patterns in the development and growth of these journals. Many of the journals have moved from just 2-3 issues per year to about 5-6 issues. In addition, the change from paper based articles to online electronic versions may have also contributed to the phenomenal increase in the total number of articles published.

The notable but less desired fall in the percentage of technical demography studies in the journals is traceable to some developments in the population field in the past two decades. Since late 1990s, teaching, training, research and further development have been observed to be diminishing. This observation has been made at two separate seminars organized six years apart by the International Union for Scientific Study of Populations (IUSSP). The first was the seminar on demographic training in the third world in 200I (Tomassini, 200I) while the second one in 2007 was focused on data needs for monitoring the Millennium Development Goals in developing countries (IUSSP, 2007). Some of the reasons adduced at the seminars include dwindling support for demographic training and imminent ageing and subsequent retirement of skilled professionals especially in developing countries (Moultrie, 2009). In response to these worrisome developments, a special meeting was convened by the IUSSP on teaching and training in applied and technical demography in developing countries in 2009 (Moultrie, 2009). At the meeting, the genesis of the problem was traced to the outcome of the 1994 International Conference on Population and Development (ICPD) after which funding for population and demography was channeled to other areas such as human rights, sexual and reproductive health. Even though the ICPD plan of action touched on population and development, it however, encouraged broad approaches such as women empowerment and human rights (UNFPA, 2004).
Two of the short-term interventions suggested at the 2009 IUSSP meeting have since been implemented. The first is a much updated web-based version of Manual X, titled "Tools for demographic estimation" (Moultrie et al., 20I3). The web-based tools for demographic estimation comprised dynamic webpages on description of the methods, rationale and data requirements as well as illustrative examples with downloadable Excel spreadsheets. It includes new methods and advances, exposition on how well each method work under different data conditions. Materials on measurement of migration from census data which was not part of Manual $X$ have been included in the web-based tool. The second intervention is an online training course on "population analysis for policies and programmes (IUSSP and UNFPA, 20I3). This online course module provides users with basic knowledge on technical population analysis. It covered topics ranging from sources, collection and evaluation of demographic data to advanced methods of demographic analysis such as model life tables, population dynamics/ projections and advanced fertility analysis.

The interdisciplinary nature of demography may have also contributed to the declining trend in technical demography. The few demographic training centres that could survive in the poor funding climates had to revise their curricular to accommodate more substantive topics in tandem with the new realities (Saxena, 20 I I). In addition, the interdisciplinary nature has made demography to be seen as a step-child of many disciplines. Thus, in many developing countries, demographic training are based in Schools of Public Health, Statistics, Sociology, Geography and Economics. Both teaching, research and practice of technical demography declined as a result of the interplay of these factors.

Another factor that may explain the decline in technical studies in demography is connected with the basic raw material which is data availability. Censuses are rarely regular and when conducted at all, they are fraught with political and technical controversies. Worst still, the census data are not made available to researchers. Recent efforts by Integrated Public Use Microdata Series - IPUMS (Ruggles et al., 2003) is yet to yield desired results. To overcome the lacuna created by challenges associated with census and VRS data, nationally representative household surveys has become very common. Interestingly, the funders and agencies implementing these surveys make the data available for further analysis. Many demographers and population scientists have had to leverage on these alternative data sources at least to keep the discipline alive. 
Demographic surveillance systems (DSS) emerged in the mid-1990s as a way to remedy the poor VRS in developing countries. Though, the contribution of DSS to our understanding about health transition is commendable (Kahn, 20II, Tollman and Kahn, 2007), it suffices to say that DSS is not a substitute for good population census or a reliable VRS, rather it should be a compliment.

\section{Limitations}

This review may have been limited due to the fact that we purposively selected only nine of available demographic journals. No doubt, some technical studies in other journals may have been left out; however, we strongly believe that the journals selected gave a fair reflection of happenings in the field of demography over the period under review.

One alternative interpretation of the findings in this review is that demography journals have expanded in scope to include a wider range of topics. It may be that the field of demography has become considerably broader, thereby making technical demography a smaller proportion of the field (and the published papers). If this was the case, it still does not override the fact that technical demography is being neglected in a subtle manner.

\section{Conclusion}

This review has shown that research and publication in technical demography is waning. As the international community pursue the post-20I5 sustainable development goals, the importance of population dynamics has reverberated across many developmental issues. For these goals to be objectively set, indicators defined and properly monitored, there is urgent need to continuously improve, enhance and apply skills in methods and techniques of demographic analysis. Training/teaching and research in technical and applied demography must be revitalized. As part of the effort to lay a solid foundation for rejuvenating the discipline, we propose a study on the assessment of demographic training to ascertain the content and quality of teaching, training and research in technical demography. Also to be investigated is the knowledge gap and teaching facilities in the training institutions.

\section{Acknowledgements}

A previous version of this manuscript was presented at the 2015 African Population Conference in Pretoria, South Africa. Comments from the chair, discussant and participants at the session are appreciated.

\section{References}

Abbas-Shavazi, M. J. 1997. An assessment of the own-children method of estimating fertility by birthplace in Australia. Journal of the Australian Population Association, 14, 167-185.

Adetunji, J. A. 1996. Infant mortality levels in Africa: Does method of estimation matter? GENUS, 52, 89-106.

Aguirre, A. 1994. Extension to the preceding birth technique. GENUS, 50, I5I-169.

Ahmed, M. F. 1995. Recent estimates of adult mortality from widowhood in Bangladesh: A critical comparison. GENUS, 5I, 97-II6.

Alkema, L., Raftery, A. E., Gerland, P., Clark, S. J., Pelletier, F., Buettner, T. and Heilig, G. K. 20II. Probabilistic projections of the total fertility rate for all countries. Demography, 48, 8I5-39.

Avery, C., St Clair, T., Levin, M. and Hill, K. 2013. The 'Own Children' fertility estimation procedure: a reappraisal. Popul Stud (Camb), 67, I7I-83.

Bairagi, R., Shuaib, M. and Hill, A. 1997. Estimating childhood mortality trends from routine data: $A$ simulation using the Preceding Birth Technique in Bangladesh. Demography, 34, 4I I-420.

Bell, M. and Stratton, M. 1998. Understanding the 1996 census migration data. Journal of the Australian Population Association, 15, I55-169.

Bhat, P. N. 2002a. Completeness of India's Sample Registration System: An assessment using the general growth balance method. Popul Stud (Camb), 56, II9-134.

Bhat, P. N. 2002b. General growth balance method: A reformulation for populations open to migration. Popul Stud (Camb), 56, 23-34.

Blacker, J., Ali, M. M. and Jones, G. 2007. A response to criticism of our estimates of under-5 mortality in Iraq, 1980-98. Popul Stud (Camb), 6I, 7-I3.

Bocquier, P. 2005. World Urbanization Prospects: an alternative to the UN model of projection compatible with the mobility transition theory. Demographic Research, 12, 197-236.

Bocquier, P., Madise, N. J. and Zulu, E. M. 20II. Is there an urban advantage in child survival in subsaharan Africa? Evidence from 18 countries in the 1990s. Demography, 48, 53I-58.

Bongaarts, J. 1999. The fertility impact of changes in the timing of childbearing in the developing world. Popul Stud (Camb), 53, 277-89.

Booth, H., Hyndman, R. J., Tickle, L. and de Jong, P. 2006. Lee-Carter mortality forecasting: a multicountry comparison of variants and extensions. Demographic Research, I5, 289-310.

Booth, H., Maindonald, J. and Smith, L. 2002. Applying Lee-Carter under conditions of variable mortality decline. Popul Stud (Camb), 56, 325-36. 
Bourbeau, R. 2000. Mortality Statistics for the Oldest-Old: An Evaluation of Canadian Data. Demographic Research, 2.

Brass, W. and Coale, A. J. 1968. Methods of analysis and estimation In: Brass, W., Coale, A. J., Demeny, P., Hiesel, F., Lorimer, F., Romaniuk, A. \& Van dan Walle, E. (eds.) The Demography of Tropica Africa. New Jersey: Princeton University Press.

Cai, Y. 2008. An assessment of China's fertility level using the variable-r method. Demography, 45, 27|-28I.

Dubuc, S. 2009. Application of the Own-Children Method for estimating fertility by ethnic and religious groups in the UK. Journal of Population Research, 26, 207-225.

Eini-Zinab, H. 20/3. Multidimensional life-table analysis of the effect of child mortality on total fertility in India, 1992-93, 1998-99, 2005-06. Popul Stud (Camb), 67, 7-23.

Elo, I. T. 200I. New African-American Life Tables from I935-I I 940 to |985-1990. 38, 97-I | 4.

Gakidou, E. and King, G. 2005. Death by survey: Estimating adult mortality without selection bias from sibling survival data. Demography, 43, 569585.

Grassly, N., Lewis, J., Mahy, M., Walker, N. and Timaeus, I. M. 2004. Comparison of householdsurvey estimates with projections of mortality and orphan numbers in sub-Saharan Africa in the era of HIV/AIDS. Popul Stud (Camb), 58, 207-2I 7.

Guillot, M. 2003. The cross-sectional average length of life (CAL): A cross-sectional mortality measure that reflects the experience of cohorts. Popul Stud (Camb), 57, 4I-54.

Hauser, P. M. and Duncan, O. D. 1959. The Study of Population: An Inventory and Appraisal, Chicago, University of Chicago Press.

Hill, K., Choi, Y. and Timaeus, I. M. 2005. Unconventional approaches to mortality estimation. Demographic Research, I3, 28I-300.

Hinde, A. and Mturi, A. J. 2000. Recent trends in Tanzanian fertility. Popul Stud (Camb), 54, I7791.

IUSSP 2007. Report of meeting on Taking stock of data needs and monitoring for the Millennium Development Goals in Developing Countries. Rabat, Morocco: IUSSP.

IUSSP and UNFPA. 2013. Population Analysis for Policies \& Programmes [Online]. http://papp.iussp.org/index.html\# I.

Kahn, K. 20II. Population health in South Africa: dynamics over the past two decades. J Public Health Policy, 32 Suppl I, S30-6.
Kannisto, V., Nieminen, M. and Turpeinen, O. 1999. Finnish Life Tables since |75|. Demographic Research, I.

Keilman, N., Pham, D. Q. and Hetland, A. 2002. Why population forecasts should be probabilistic illustrated by the case of Norway. Demographic Research, 6, 409-454.

Keyfitz, N. 1993. Thirty Years of Demography and Demography. Demography, 30, 530-548.

Kohler, H. and Ortega, J. A. 2002. Tempo-adjusted period parity progression measures, fertility postponement and completed cohort fertility. Demographic Research, 6, 9I-I44.

Kostaki, A. and Panousis, V. 200I. Expanding an abridged table. Demographic Research, 5, I-22.

Masquelier, B. 2013. Adult mortality from sibling survival data: a reappraisal of selection biases. Demography, 50, 207-28.

Mathers, D. C., Fat, D. M., Inoue, M., Rao, C. and Lopez, A. D. 2005. Counting the dead and what they died from: an assessment of the global status of cause of death data. Bulletin of the World Health Organization, 83, I7I-I80.

Miller, T. and Lee, R. 200I. Evaluating the performance of the Lee-Carter Method for Forecasting Mortality. Demography, 38, 537-549.

Moultrie, T. A. 2009. IUSSP/UNFPA meeting on Applied and Technical Demographic Training in Developing Countries: Towards an Agenda for Revitalisation.

Moultrie, T. A. and Dorrinton, R. 2008. Sources of error and bias in methods of fertility estimation contingent on the P/F ratio in a time of declining fertility and rising mortality. Demographic Research, 19, 1635-1662.

Moultrie, T. A., Dorrinton, R., Hill, A., Hill, K., Timaeus, I. M. and Zaba, B. 2013. Tools for Demographic Estimation, http://demographicestimation.iussp.org/, IUSSP and UNFPA. Moultrie, T. A., Sayi, T. S. and

Timaeus, I. M. 20I2. Birth intervals, postponement, and fertility decline in Africa: a new type of transition? Popul Stud (Camb), 66, 24I-58.

Moultrie, T. A. and Timaeus, I. M. 2003. The South African fertility decline: Evidence from two censuses and a Demographic and Health Survey. Popul Stud (Camb), 57, 265-83.

Nath, D. C. and Choudhury, L. 1995. Two regional (rural-urban) Life Tables for India. GENUS, 5I, 45-67.

Odimegwu, C. O. and Zerai, A. 1996. Undertstanding the proximate determinants of fertility of a Nigerian ethnic group. GENUS, 52, 67-87. 
Paget, W. J. and Timaeus, I. M. 1994. A Relational Gompertz Model of Male Fertility" Development and Assessment. Popul Stud (Camb), 48, 333-340.

Pali, L. 2015. Whither indirect demographic estimation methods: Africa's data revolution coming of age. Population Association of America Annual Meeting. San Diego

Preston, S. H., Elo, I. T. and Stewart, Q. 1999. Effects of age misreporting on mortality estimates at older ages. Popul Stud (Camb), 53, 165-I 77.

Ramakumar, R. and Gopal, Y. S. 1986. Technical Demography, New Delhi, Wiley Eastern Limited.

Rowland, D. T. 1996. Cohort survival in ageing popultions: A model life table approach. GENUS, 52, 7I-82.

Ruggles, S., King, M. L., Levison, D., McCAA, R. and Sobek, M. 2003. IPUMS-International. Historical Methods, 36, 60-65.

Sastry, N. 1997. Family-level clustering of childhood mortality risk in Northeast Brazil. Popul Stud (Camb), 5I, 245-26I.

Saxena, P. C. 20II. COMMENTARY- The dying art of Technical Demography. Asian Population Studies, 7.

Sibanda, A. 1999. The Kenyan fertility transition: An age-specific analysis of fertility levels and trends. GENUS, 55, I53-194.

Spoorenberg, T. 2008. What can we learn from indirect estimations on mortality im Mongolia, 1969-1989? Demographic Research, 18, 285-310.

Thomas, J. R. and Clark, S. J. 20II. More on the cohort-component model of population projection in the context of HIV/AIDS: A Leslie matrix representation and new estimates. Demogr Res, 25, 39-I02.

Tollman, S. M. and Kahn, K. 2007. Health, population and social transitions in rural South Africa. Scand J Public Health Suppl, 69, 4-7.

Tomassini, C. 200I. Report of Seminar on Demographic Training in the Third Millennium. IUSSP.
Udjo, E. O. 1998. Trends in level and tempo of fertility in Botswana. GENUS, 54, 285-30I.

Udjo, E. O. 2013. Estimating South Africa's black adult female social classes, demographic differentials and determinants. GENUS, 69, I-23.

Udjo, E. O. 2014. Estimating demographic parameters from the 20I I South Africa population census. African Population Studies, 28, 564-578.

Udjo, E. O. 20I5. Projecting population, numbers of households and dwelling units in South Africa 20I I-202I. African Population Studies, 29, 15 II1526.

UNFPA 2004. Programme of Action Adopted at the International Conference on Population and Development, Cairo, 5-I3 September 1994.

United Nations 1983. Manual X: Indirect techniques for demographic estimation, New York, Department of International Economic and Social Affairs.

Williams, A. O. 2014. Assessment of the completeness of births and deaths registration in an urban Nigerian community. African Population Studies, 27, 263-272.

Wilson, T. 2010. Model migration schedules incorporating student migration peaks. Demographic Research, 23, 191-222.

Wisniowski, A., Smith, P. W., Bijak, J., Raymer, J. and Forster, J. J. 2015. Bayesian Population Forecasting: Extending the Lee-Carter Method. Demography, 52, 1035-59.

Xie, Y. 2000. Demography: Past, Present, and Future. Jounal of the American Statistical Association, 95.

Zaba, B. and Paes, N. 1995. An alternative procedure for fitting relational model life tables. GENUS, 5I, 19-43.

Zhao, B. B. 2012. A modified Lee-Carter model for analysing short-base-period data. Popul Stud (Camb), 66, 39-52. 